\title{
Operationalizing and scaling up HIV/RH referrals in Kenya: The way forward
}

APHIA II OR Project in Kenya

Follow this and additional works at: https://knowledgecommons.popcouncil.org/departments_sbsr-rh

Part of the Demography, Population, and Ecology Commons, Family, Life Course, and Society Commons, Immune System Diseases Commons, International Public Health Commons, Maternal and Child Health Commons, Virus Diseases Commons, and the Women's Health Commons How does access to this work benefit you? Let us know!

\section{Recommended Citation}

"Operationalizing and scaling up HIV/RH referrals in Kenya: The way forward," APHIA II Operations Research Project in Kenya Policy Brief. Nairobi: Population Council, 2011.

This Brief is brought to you for free and open access by the Population Council. 


\section{APHIA II OR Operations Research Project in Kenya}

Policy Brief No. I

\section{Operationalizing and scaling up HIV/RH referrals in Kenya: The way forward}

Integration of HIV/AIDS and reproductive health (RH) services is considered one effective strategy to improve access to and efficiency of health delivery systems. Kenya's government has developed national guidelines and strategies for HIV testing and counseling as well as the integration of HIV and RH services ${ }^{1,2}$; both documents emphasize the need to provide coordinated and integrated services across the HIV and RH divisions. However, many HIVpositive family planning (FP) clients have not been actively linked to important HIV services, including anti-retroviral treatment, screening and management of sexually transmitted infections (STIs). Without comprehensive and systematic referrals, these clients may not access these services.

Through APHIA II OR Project, Population Council and Kenya's Ministry of Health developed and tested an approach to systematically link HIV-positive FP clients to treatment and care services. Intervention activities were implemented from November 2009 to May 2010 in six facilities of Central Province. Key activities included provider training and testing of referral package which showed how, where, when and who is to make and receive referrals. The following two tools served as the crux of this referral package:

- A referral directory listing all facilities in the vicinity available for services including HIV counseling and testing, FP, STIs, tuberculosis, and well-child checks. Clients select the most appropriate referral site according to their needs and preferences.

- Referral forms at all referring facilities directing clients to appropriate receiving clinics.

Results showed that $93 \%$ of the HIV positive FP clients referred from MCH/FP clinics were received in HIV care and treatment centers. In addition, $96 \%$ of providers reported discussing referral with HIV-positive FP clients (up from $71 \%$ at baseline). Not only did this operations research study demonstrate success in properly linking HIV-positive clients to treatment and care, but use of the referral tools validated that indeed patients were properly received at sites and allowed for documentation and monitoring of the referral process.

A dissemination meeting was convened by the $\mathrm{MOH}$ in March 2011 to share evidence of the program's success and frame the way forward. Participants included research partners, national stakeholders from HIV, STI, and reproductive health sectors, provincial and district health management teams. Together, they discussed some of the challenges presented, promising best practices and key conditions and factors that could facilitate the model's adoption and scale-up. Participants emphasized that in order to successfully operationalize this intervention on a larger scale, the following critical conditions should be met:

\section{Leadership from Ministry of Health}

The referral system was implemented in Central Province by district health and hospital management teams, demonstrating the great potential for its sustainability and replication. With interest and commitment from the $\mathrm{MOH}$, this intervention can easily be scaled up and integrated into existing national guidelines with little assistance from outside resources. 


\section{Strong linkages between health services}

A good referral system requires strong and consistent linkages between referring and receiving institutions. Referral tools strengthen linkages between services by providing clear cut instruction for clients and providers. In addition, communication and interrelationships between staff in facilities greatly increase staff's knowledge of other existing facilities and services and improve feedback from the system.

\section{Consistent commodities and supplies}

To ensure high quality services in both referring and receiving institutions, commodities and supplies must be available. An HIV infection cannot be detected without an HIV test kit, FP services cannot be provided without a range of methods available for the woman to choose from, and CD4 counts cannot be measured without laboratory supplies. In order to reduce missed opportunities and provide high quality services, commodity security is requisite.

\section{Supportive supervision and well-trained staff}

A critical mass of health providers should be trained on referral within the facilities in order to improve coverage of these services. Provider trainings and updates will help to streamline new processes and improve coverage of referral services within and between health facilities.

Motivation and supervision from the Division of Reproductive Health, NASCOP, provincial, district and health facility management teams can support these new endeavors.

\section{Streamlined data management systems}

In addition to its role in guiding clients to referral facilities, the referral tool allows for systematic record keeping and data collection in facilities and within provincial systems. When compiled by district health management teams, they serve as the source of information to monitor and track the referral system. Streamlining the format of the tool and the national health systems software will facilitate efficient data collection and monitoring of the referrals.

\section{Leveraged resources}

Success of the referral system in Central Province would not have been possible without partnership from service delivery stakeholders to train and roll out the program. Under leadership from the $\mathrm{MOH}$, bilateral service delivery programs, NGOs and private sector institutions can join efforts to support this scale-up by sharing costs of local dissemination meetings, trainings, and coordination. Together, health services can be efficiently and actively linked and national health programs can work together to improve the lives of all Kenyans.

The results of the study showed that the referral framework put in place to systematically link HIV-positive FP clients to care and treatment services was feasible, acceptable and effective in all the participating health facilities. Successful replication and scale-up activities of an effective referral system can only be realized if key conditions such as leadership from $\mathrm{MOH}$, functional partnership, and a revitalized pipeline of commodities and supplies, are in place.

\footnotetext{
' National AIDS and STI Control Programme, Republic of Kenya Ministry of Health and Sanitation. 2008. National Guidelines for HIV Testing and Counseling in Kenya.

${ }^{2}$ National Reproductive Health and HIV \& AIDS Integration Strategy, August 2009; National AIDS and STI Control Programme and the Division of Reproductive Health, Republic of Kenya.
}

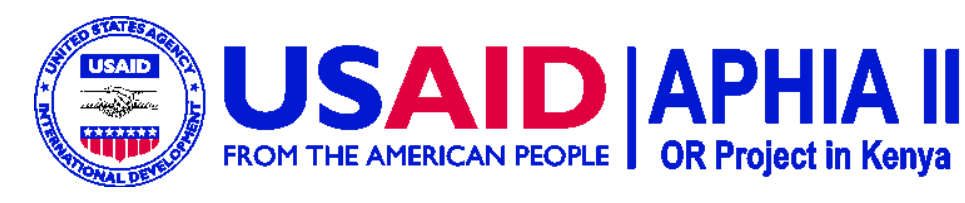

